\title{
Cardiac involvement of Wegner granulomatosis: It's rare but not unheard of
}

\author{
Oliver J. Liakopoulos, MD
}

\author{
From the Department of Cardiothoracic Surgery, Heart Center, University of Cologne, Cologne, Germany. \\ Disclosures: Author has nothing to disclose with regard to commercial support. \\ Received for publication March 22, 2018; accepted for publication March 27, 2018; available ahead of print April \\ $24,2018$. \\ Address for reprints: Oliver J. Liakopoulos, MD, Department of Cardiothoracic Surgery, Heart Center of the Uni- \\ versity of Cologne, Kerpener Strasse 62, Cologne 50924, Germany (E-mail: oliver.liakopoulos@uk-koeln.de). \\ J Thorac Cardiovasc Surg 2018;156:e99-100 \\ $0022-5223 / \$ 36.00$ \\ Copyright (C) 2018 by The American Association for Thoracic Surgery \\ https://doi.org/10.1016/j.jtcvs.2018.03.105
}

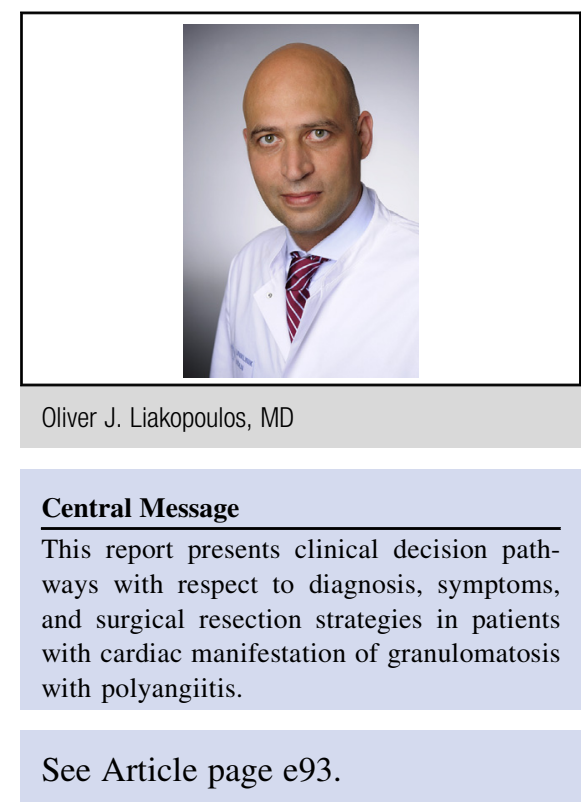

reconstruction of the mitral annulus and left atrium after valve replacement. The pathological findings of the specimen confirmed a chronic necrotizing granuloma highly suggestive for GPA.

The authors can be congratulated for their aggressive approach, which seems justified on the basis of the excellent surgical results and uneventful postoperative course of all patients. Importantly, this case series underscores that treatment of GPA-associated cardiac lesions is feasible and can be safely performed. As a prerequisite for successful surgery, preoperative imaging (computed tomography, magnetic resonance imaging) seems to be imperative to identify the exact anatomical position and feasibility of surgery, and to exclude other malignant cardiac mass entities (lymphomas, sarcoma, etc), that might be a contraindication for cardiac surgery and/or more amendable to conservative treatment strategies. Finally, although surgery seems to be a viable option for GPA-associated cardiac lesions the long-term results of this chronic autoimmune disease including late cardiac recurrence despite surgery and optimal immunosuppressive therapy is still largely unknown. Nonetheless, we cardiac surgeons need to be aware of this rare but treatable cardiac disease.

\section{References}

1. Kasper DL, Fauci AS, Hauser SL, Longo DL, Jameson JL, Loscalzo J. Harrison's Principles of Internal Medicine. 19th ed. New York: McGraw Hill Education; 2015. 
2. Grant SC, Levy RD, Venning MC, Ward C, Brooks NH. Wegener's granulomatosis and the heart. Br Heart J. 1994;71:82-6.

3. Lacoste C, Mansencal N, Ben M'rad M, Goulon-Goeau C, Cohen P, Guillevin L, et al. Valvular involvement in ANCA-associated systemic vasculitis: a case report and literature review. BMC Musculoskelet Disord. 2011;12:50.
4. Colin GC, Vancraeynest D, Hoton D, Jonard P, Gerber B. Complete heart block caused by diffuse pseudotumoral cardiac involvement in granulomatosis with polyangiitis. Circulation. 2015;132:e207-10.

5. Abe N, Takahashi H, Inoue T, Tanaka H, Okita Y. Wegner granulomatosis of the heart. J Thorac Cardiovasc Surg. 2018;156:e93-7. 